МИХЕЕВА Татьяна Борисовна доктор педагогических наук, профессор кафедры «Мировые языки и культуры» Донского государственного технического университета, Ростов-на-Дону, Российская Федерация Tatyana B. MIKHEEVA Dr. Sci. (Theory and Methodology of Vocational Education), Prof.,

Don State Technical University, Rostov-on-Don, Russian Federation, mitata.m@yandex.ru

ORCID: 0000-0001-9773-1368

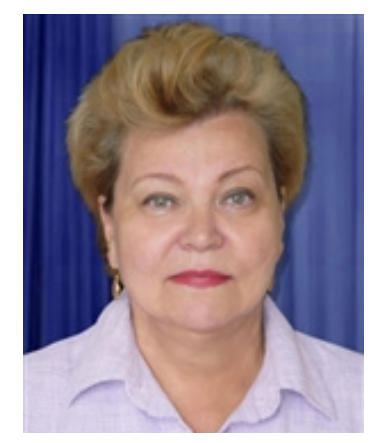

САЪДУЛЛАЕВ Давлятбек Самиевич кандидат филологических наук, профессор кафедры русского языка и методики преподавания Ташкентского государственного педагогического университета имени Низами, Ташкент, Республика Узбекистан Davlatbek S. SADULLAYEV Cand. Sci. (Philology), Prof., Nizami Tashkent State Pedagogical University, Tashkent, Republic of Uzbekistan, uz-samizade@mail.ru

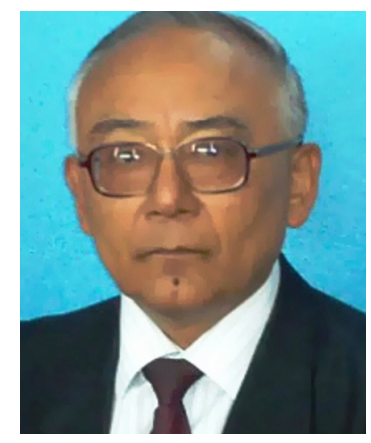

\section{Личность в мире родной культуры и общечеловеческих ценностей}

\author{
Personality in the World \\ of Culture of Origin \\ and Universal Values
}

Цель статьи - выявление и комплексное описание ключевых реалий и понятий культурно-тематического микрополя «узбекский быт». Методология строится на системном обобщении и сопоставлении семантики этнокультурных реалий, выраженных посредством неэквивалентных лексических единиц. Материалами исследования явились этнографические данные о культуре узбекского и башкирского народов, исследования культурологов и лингвистов. Многовековые контакты между представителями разных этносов, проживающих на одной территории, как правило, отражаются в языковом фонде. Была проанализирована неэквивалентная и неполноэквивалентная лексика узбекского и башкирского языков, при этом выделен массив 
важнейших этнокультурных реалий узбекского быта. Национальные языки дают ключ к пониманию особенностей этнического самосознания, однако в лингвокультурном плане полноценное вхождение каждого языка и каждого народа в мировую культуру есть звено, упрочивающее взаимопонимание между представителями различных этносов.

Ключевые слова: этнос, особенности быта, человек культуры, культурологическая парадигма, реалии культуры, межкультурное взаимодействие, общечеловеческие ценности, менталитет.

C конца XX в. содержание науки меняется в сторону интеграции лингвофилософии (языковая картина мира) и культурологии (новый диалогический тип культуры), взаимопроникновения и взаимообогащения присущих им систем познания. В современных условиях гуманитарная теория и практика неуклонно повышают свое внимание к этнокультурной стороне проблем существования и развития общества, в частности к лингвистическим и культурным контактам этносов, обусловленным долгим совместным проживанием на одной территории. Их исторические взаимодействия, взаимовлияния отражаются в зеркале языка и накладывают на языки отпечаток не механический, внешний, в виде различного рода заимствований, но более глубокий, внутренний [3].

Современная культурологическая парадигма гуманитарных наук актуализирует изучение и описание человека культуры как личности, стремящейся к взаимопониманию с представителями других этносов, способной осуществлять межличностное и межкультурное общение, в том числе и посредством международных языков. Как показывает мировой опыт, в стратегиях аккультурации личности наряду с овладением культурой других этносов важно и сохранение собственной культурной идентичности. «С этим багажом каждый народ, регион входит в новую мировую семью человечества... в будущей семье народов будет цениться не то, что мы как все, а то, что мы особенные. То есть мы одновременно находимся в русле цивилизованного развития, но при этом должны сохранить свою самобытность» [5, c. 3].

В контексте нашего исследования понятие «культура» (исторически формирующаяся и развивающаяся система духовных образований, которой определены основные черты поведения человека, доминанты его отношения к миру) целесообразно сочетать с понятием «поликультурность» (выраженное как спектр, не стертое многообразие, одновременная представленность разных самобытных и уникальных культур) [2].

Современная личность включена в мир родной и общечеловеческой культуры, готова к сотрудничеству, толерантности и уважению к другим национальным культурам. Формирование такой личности предполагает высокий уровень коммуникативной культуры, что в межкультурном измерении включает в себя приверженность ценностям общечеловеческим, понимание важнейших особенностей культуры национальной и мировой, а также учет культурологического базиса социальных явлений и традиций. Говоря об общечеловеческих ценностях, мы, прежде всего, имеем в виду ценности нравственные: труд, красоту, добро, справедливость, любовь, жизнь, истину, родину, семью, свободу, человека. Эти ценности, одинаково важные для всех, объединяют нас, живущих на Земле, в единое человечество и обеспечивают мосты взаимопонимания между представителями разных языков и культур. В своем отборе контента мы руководствовались необходимостью включения тех лингвокультурем и того культурно значимого материала, которые, будучи известными всем носителям языка, помогают, с одной стороны, усвоить черты национального образа жизни, с другой - обеспечить его полноценную репрезентацию в межкультурной коммуникации.

Интенсивность современного межкультурного общения обязывает заботиться о под- 
держке и сохранении традиций всех без исключения народов, больших и малочисленных.

Богатый и интересный материал представляет собой своеобразный уклад жизни башкир и узбеков, веками формировавшийся на границе Европы и Азии, в условиях пересечения культур оседлых с культурами кочевыми и под влиянием различных вероисповеданий - в частности, ислама и православного христианства. Он находит отражение в текстах национальных и русских писателей. Помимо свадебного празднества (туй) известны мусульманские религиозные праздники: ураза-байрам, курбан-байрам, мавлид и другие. По окончании весенне-полевых работ отмечаются сабантуй и каргатуй («грачиный праздник»). Праздничные ритуалы сформировались в результате сложного процесса слияния культурных навыков и традиций. Яркие и многообразные самобытные традиции закреплены в обрядах, сопровождающих семейную жизнь, - свадебные ритуалы, события, связанные с рождением и воспитанием детей (бешик-туйи, хатна-килиш, фатиха-туй). Они зародились еще в лоне родоплеменных патриархальных отношений, поэтому, как правило, исламская обрядность дополнена в них более древними формами, тесно переплетена с магическими практиками.

Группы концептов культурно-тематического микрополя «узбекский быт», «башкирский быт» подтверждают близость комплекса доминант, того, что являет собой непреходящие ценности в культуре этих родственных народов. Черты глубинного исторического пласта - многовекового жизненного опыта, сохраненного народной памятью до сегодняшнего дня, играют ключевую роль в осмыслении понятий «дом», «домашний очаг» и соответствующего им круга традиционных семейных нравственных норм.

Надо подчеркнуть, что национально-культурные особенности быта узбеков, башкир и других тюркоязычных народов характеризует лексика безэквивалентная (махалля, хашар, сумалак, улок - узб.; улус, кош, корот - башк.), либо неполноэквивалентная, то есть слова, обозначающие предметы и реалии, не совпадающие в разных культуpax по предметно-понятийному значению, однако поддающиеся переводу на другие языки. В пример неполноэквивалентной лексики можно привести слова кишлак (узб. кишлок) и аул (башк. ауыл) - названия селений, имеющие неполным своим эквивалентом русские слова «селение», «деревня».

Приведем еще ряд примеров.

- Чувал (башк. сыуал) - глинобитный очаг с вмазанным котлом, род азиатского камина, очаг (узб. учок) - глинобитный очаг. Котел служил для приготовления пищи, однако в нем же башкиры кипятили воду для стирки, зачастую и стирали. Чувал (сыуал) сооружали посредине коша (юрты, избы) так, чтобы очаг не чадил: дым поднимался прямо в отверстие, расположенное на потолке. Этот очаг обогревал помещение, и около него проходила большая часть домашней жизни башкирского семейства. Очаг был также связан с обычаями гостеприимства: собравшись вокруг сыу$a$, башкиры (только мужчины) пили кумыс и слушали песни.

- Кошма - войлок из скатанной овечьей или верблюжьей шерсти (русский эквивалент - ковер).

- Уй (узб., башк.) - бревенчатое строение, крытое дранкой (русский эквивалент изба, дом).

- Казан (узб. козон) - чугунный котел, который выпускали российские заводы специально для кочевых народов (русский эквивалент - котел), но с исторических времен тюркоязычные народы и племена использовали такие котлы, изготовленные местными мастерами-литейщиками.

Жилище - зеркало, отражающее жизнь народа, которому оно принадлежит. На устройстве и убранстве жилища прочитывается природная среда, развитие производительных сил и характер общественного строя, тип и уровень цивилизации, этнические и национальные черты, духовные качества, верования, таланты и наклонности каждого народа. Как локус оно отражает структуру и особенности жизни различных слоев населения, нравы, привычки, вкусы - определяет менталитет [4].

Сформировавшаяся в народном жилище среда является результатом материальных и духовных устремлений человека. Предмет- 
ный мир аккумулирует традиции ремесел. Важно также то, что среда эта создается не только руками талантливых мастеров-ремесленников, одаренных художников из народа, но и личным участием самих членов семьи. Навыки передаются от одного поколения к другому.

В каждом доме женщины были не только хранительницами очага, но и обязательными проводниками - передатчицами, активными носительницами знаний и навыков традиционной культуры. В этом смысле вся атмосфера дома - характер, образ жизни выступали своеобразной школой и трудового, и нравственного, и эстетического воспитания в духе народных национальных традиций, лоном органичного вхождения в свою родную культуру [6].

Предметы интерьера, их неразрывная связь с окружающей средой и с человеком формируют эту целостность. Метод системного комплексного анализа, разработанный Л.Н. Гумилевым, считавшим, что «...реально существующим фактором системы являются не предметы, а связи между ними» [1 с. 209], позволяет рассматривать среду бытования народного искусства в единстве с природно-климатическими и хозяйственно-экономическими условиями, сферой культурной, духовной жизни, самим человеком - творцом и созидателем, представляющим данный этнос.

Приведем и более развернуто охарактеризуем примеры наиболее значимых этнокультурных реалий узбекского народа.

Махалля - объединение людей, соединенных незримыми узами общности территории, на которой они проживают. Дать достойный эквивалент понятию «махалля» жителю западных стран практически невозможно, ибо там его просто нет. А для личности местного типа махалля, как правило, выступает неотъемлемой частью человеческого бытия от рождения и до смерти. Это уникальное явление узбекского этноса соединяет с реалиями современного города патриархальные особенности сельской жизни, когда все жители кишлака знают друг друга. Это и своеобразная форма восточной демократии, которая дает человеку возможность выработать методы взаимодействия с обществом и государством. Здесь зарождаются первые узы дружбы, кото- рые потом проходят через всю жизнь. Здесь все вместе отмечают праздники, печалятся горестям и невзгодам.

С понятием «махалля» неразрывно связано понятие «хашар». Когда люди, объединившись по зову сердца и соседского долга, строят дом, играют свадьбу, провожают в последний путь, это называется хашар. Принадлежность к махалле как некой целостности придает человеку силы, делает его более устойчивым в бурном море житейских проблем и забот. Сегодня роль махалли как одного из гарантов стабильности всего общества в Узбекистане вновь существенно возрастает. Неслучайно 2003 г. указом первого президента Республики Узбекистана Ислама Каримова был объявлен Годом махалли.

Узбекский народ за свою историю накопил немало удивительных традиций и обычаев. Одна из них - приготовление национального блюда сумалак (сумаляк). Без него не обходится весенний праздник Навруз: «Сто казанов сумаляка готовят в кишлаках древнего Вуодиля» (Правда Востока. 2009. 21 мар.). Его рецепт бережно передается из поколения в поколение.

Он прост и в то же время необычен. Зерна пшеницы тщательно промывают и влажными складывают в холщовый мешок, который хранят в теплом месте. Ежедневно в течение четырех дней мешок обливают водой, после чего набухшую пшеницу вынимают, раскладывают на чистых досках и поливают водой четыре раза в день. После того как пшеница прорастет на 4-5 см, ростки мелко рубят, а затем толкут в деревянной ступе. Полученную массу - майсу - процеживают через сито. Образовавшуюся жидкость сохраняют, а оставшуюся гущу несколько раз тщательно промывают в большом количестве воды и процеживают. Затем эту массу выливают в большой казан, туда же засыпают муку, добавляют топленое сливочное масло. Эту смесь (атала) долго, подчас с вечера до утра, варят, постоянно перемешивая. В кипящем котле можно различить странный звук, как будто по дну перекатываются камешки. Да, это действительно так. Камешки кладут, чтобы устранить опасность подгорания. А чтобы облегчить ночное бдение у котла, монотонное и весьма утомительное, исста- 
ри заведен такой обычай. Женщины, а варка сумалака только их прерогатива, играют на музыкальных инструментах, поют, танцуют. Под утро, после десятичасовой варки, в котел добавляют оставшуюся от первого процеживания жидкость - тонг суви (вода восхода, рассветная вода) и дают еще раз закипеть плотной коричневого цвета и неповторимого вкуса смеси. После этого огонь из-под казана убирают, котел, плотно закрытый крышкой, оставляют еще на 3-4 часа.

Результат огромного терпения и кулинарного искусства сумалак - одно из самых витаминизированных блюд узбекской кухни. Оно готовится раз в год, ранней весной, когда организм человека особенно нуждается в подпитке силами. Готовый сумалак распределяют так, чтобы он достался всем, кто участвовал в приготовлении блюда или внес свою долю продуктов - пшеницу, муку, масло. Эти люди, в свою очередь, угощают праздничным блюдом родственников и знакомых, разнося сумалак по домам в пиалах или другой красивой посуде.

Туморы. Среди немногих атрибутов быта, прошедших с человеком сквозь многие века, дошли до нас туморы - амулеты, которым приписывалась способность оберегать владельца от болезней, бедствий, враждебных чар. Амулеты издревле были известны народам, населявшим территорию современного Узбекистана. Археологические находки показывают, что ими пользовались еще до нашей эры, во времена язычества. Модницы прежних веков украшали руки амулетами в виде змей-браслетов, носили амулеты на груди, использовали в виде налобных и подвисочных украшений, вплетали в косы, нашивали на детскую одежду, украшали ими стены жилищ. Из чего только ни делали амулеты: из металла, керамики, дерева, дорогой материи, из косточек фруктовых деревьев. Очень часто на них наносились изображения животных и птиц. Туморы наиболее древнего, первоначального вида сейчас можно встретить лишь в музеях, да еще в коллекциях художников, возрождающих забытое искусство.

Обычай наносить рисунки живых существ с приходом в Среднюю Азию ислама исчез. Появились строгие канонизированные туморы. В наши дни это чаще всего небольшие по размеру треугольные подушечки из бархата, парчи, тафты с вшитыми внутрь зернами растения (седана) или же с изречениями из Корана. Их украшают бисером и как оберег подвешивают на стенах внутри дома, в автомашинах, прикрепляют к одежде ребенка.

Улак (улок) - козлодрание. По отмашке судьи всадники срываются с места и под неистовые крики болельщиков наперегонки скачут вперед. Тот, кому удалось опередить соперников и вырваться из лавины, подхватывает на скаку тушу козла. Остальные всадники пытаются отнять поднятый с земли трофей. За их борьбой наблюдают многочисленные зрители: узбекский улак еще называется куnкари — буквально «дело многих людей».

Этот вид конного спорта популярен не только у узбеков, его считают «своим» также и соседние народы - казахи, кыргызы, афганцы, таджики, каракалпаки. У каждого из перечисленных народов это традиционное соревнование в лихости и умении наездников именуется по-своему. Однако суть и цель состязания, при некотором различии правил, одинакова: надо на скаку поднять тушу козла с земли и, не дав соперникам перехватить инициативу, доставить добычу к финишу.

Улак - праздник степняков-коневодов - стал традиционным в Центральной Азии с незапамятных времен: лошадей здесь разводят не один век и не одно тысячелетие. Еще китайские императоры до нашей эры отряжали экспедиции в Ферганскую долину за породистыми конями. Зарафшанский оазис (Самарканд, Ургут, Каттакурган) славен как один из древних районов коневодства. Хотя разводили разные породы, наиболее знаменитой была карабаирская.

И приемы отбора, подготовка лошадей к соревнованиям также несут отпечаток традиции. Как коней для улака молодняк отбирают и готовят с четырех-пяти лет.

Наиболее яркий и массовый улак - свадебный. На него съезжаются жители со всей округи, родственники из ближайших и отдаленных мест. Время свадеб в основном начинается со второй половины осени, когда уже собрали урожай, и продолжается всю 
зиму, вплоть до ранней весны (до начала сельхозработ).

Помимо лошадей к улаку требуется заранее приготовить жертвенных животных козлов или бычков. Непременно нужны и награды победителям. Помимо живых призов, таких как верблюды, лошади, быки, козы, победителей награждают коврами, отрезами ткани, мастерски изготовленными и украшенными предметами быта.

Начало улака также имеет свою особенность. Гостей созывает глашатай, который от имени хозяев свадьбы просит отведать праздничного плова или шурпы. Когда трапеза завершена, старейшина-аксакал должен от имени всех собравшихся дать благословение игре. Седокам нельзя садиться на коня, не совершив ритуальное омовение и молитву. Одеждой всадникам служит широкий чапан (халат) из очень плотной хлопковой ткани и такие же плотные шаровары. Главное, чтобы наряд седока не сковывал движения. Прежде чем надеть сапоги с широкими голенищами, ноги обматывают тканью - во избежание травм при возможном падении с лошади. На голову седокам надевают меховые шапки (иногда, особенно в последнее время, кожаные шлемы). Есть и другое современное дополнение - на одежду игроков нашивают номера (как на майки футболистов).

При экипировке лошадей используются уздечки без металлических деталей, гладкие стремена. Нельзя участвовать в соревновании коням с шипованными подковами.

Для проведения улака выбирают широкую равнинную местность, позволяющую разместить в полутора километрах друг от друга две круговые площадки. Это финишные отметки марра - круг, в который всадник-победитель вбросит тушу козла. Периметр кругов (по диаметру около 20 м) выкладывают камнями или большими пучками соломы. Так же отмечают и черту, разделяющую игровое пространство надвое: на этой границе располагаются главный судья и его помощники.

Каковы правила игры? Наездникам запрещено заезжать за границы игрового поя и наезжать на зрителей. Ни один болельщик не должен притрагиваться к туше козла, перемещать ее или подавать с земли всаднику. Если наездник нагнулся за тушей, другие игроки не имеют право наезжать лошадью на него. Тушу отнимают только на полном скаку. При этом соперник должен заехать лицом к лицу к тому, кто в данный момент захватил трофей. При заезде со спины игрок должен догнать, опередить и только потом вступать в борьбу за тушу козла. И сваливать с лошади того, кто держит в руках трофей, тоже запрещено.

Интерес к этой древней игре, ее возрождение наблюдается примерно с 1990-х гг. Учреждена Международная спортивная федерация, членами которой являются республики Центральной Азии, Пакистан, Турция, Китай, Франция. И в международных соревнованиях, проходящих по командному принципу, на данный момент утвержден определенный свод правил: игра продолжительностью 60 минут включает в себя три периода по 20 минут. Побеждает та команда, которая большее число раз забросит тушу козла в той-казан соперника (спортивный вариант оборудования финиша). Игрока-наездника, персонально лидировавшего в победившей команде, признают абсолютным победителем. Хотелось бы, чтобы со временем эту игру включили в число олимпийских дисциплин.

Все приведенные этнокультурные реалии важны как имманентные данности национально-культурного быта. Описание, изучение, полноценная реставрация их особенностей - фактор сохранности этнических культур в современном мире. В языке народа живут и воздействуют на него духовное содержание и знание. Язык отражает менталитет, традиции и историю каждого народа, становится носителем культуры. Как отражение и копилки национального опыта языки несут и содержат в себе ключ к самоидентичности народов. Но в плане лингвокультурном полноценное вхождение каждого языка и каждого народа в мировую культуру есть звено, упрочивающее взаимопонимание между представителями различных этносов. 
Tatyana B. MIKHEEVA

Dr. Sci. (Theory and Methodology of Vocational Education), Prof., Don State Technical University,

Rostov-on-Don, Russian Federation,

mitata.m@yandex.ru

Davlatbek S. SADULLAYEV

Cand. Sci. (Philology), Prof., Nizami Tashkent State Pedagogical University,

Tashkent, Republic of Uzbekistan,

uz-samizade@mail.ru

\section{Personality in the World of Culture of Origin and Universal Values}

Abstract. The aim of the article is to identify and comprehensively describe the key realities and concepts of the cultural and thematic microfield "Uzbek Domestic Life". The methodology is based on a systematic generalization and comparison of the semantics of ethnocultural realities expressed through nonequivalent lexical units. The research materials were ethnographic data on the culture of the Uzbek and Bashkir peoples, studies of culturologists and linguists. Domestic life is interpreted as a historically formed, evolving system of spiritual education that defines the characteristics of the behavior of a person of culture and their attitude to basic life values. The authors proceed from the fact that a reference to universal values and an understanding of the significance of the heritage of the past (not only of one's own people, but also the peoples of other countries) create mutual understanding between representatives of different ethnic groups and promote intercultural communication. At the same time, centuries-old linguistic and cultural contacts between representatives of different ethnic groups living in the same territory are usually reflected in the language fund. The key to uncovering the value layer of the most capacious ethnocultural realities is the nonequivalent and incompletely equivalent vocabulary of related languages. To achieve the aim of the research, the lexical units of the Uzbek and Bashkir languages were analyzed. It is shown how the studied lexical layer affects the understanding of fundamental life concepts: "family hearth", "house", and associated traditional moral standards. An array of the most important ethnocultural realities has been singled out, which immanently reflects the social structure, the peculiarities of Uzbek life, which determine the mentality, mores, customs, habits, and tastes of the people. This array consists of: mahallah (a union of people connected by the invisible bonds of good neighborliness and the community of the territory in which they live); hashar (joint activity of people); sumalak (a national dish of sprouted wheat grains); tumor (an amulet attributed to the ability to protect the owner from evil); ulak ("goat pulling", an ancient folk game, revived to the level of international competition). The authors conclude that languages as a reflection of national experience provide the key to understanding the characteristics of ethnic identity. At the same time, in linguistic and cultural terms, the full integration of every language and every nation into world culture is a link that strengthens mutual understanding between representatives of different ethnic groups.

Keywords: ethnos, lifestyle peculiarities, person of culture, culturological paradigm, cultural realities, cross-cultural interaction, universal values, mentality.

\section{Использованная литература:} 2013.

1. Гумилев Л. Н. Древние тюрки. М.: Айрис-пресс,

2. Дмитриев Г. Д. Многокультурное образование. М.: Народное образование, 1999.

3. Млечко Т. П. Индивидуальное когнитивное пространство русской языковой личности в новом зарубежье // Русский язык за рубежом. 2012. № 1. С. 58-64.

4. Спегальский С. П. Жилище Северо-Западной Руси IX-XIII вв. Л.: Наука, 1972.

\section{References:}

1. Gumilyov, L.N. (2013) Drevnie tyurki [Ancient Turks]. Moscow: Ayris-press.

2. Dmitriev, G.D. (1999) Mnogokul'turnoe obrazovanie [Multicultural Education]. Moscow: Narodnoe obrazovanie.

3. Mlechko, T.P. (2012) Individual Cognitive Space of the Russian-Speaking Personality in the New Identity Abroad. Russkiy yazyk za rubezhom - Russian Language Abroad. 1. pp. 58-64. (In Russian). 
5. Степин В. С. Эпоха перемен и сценарии будущего. М.: Ин-т философии Рос. акад. наук, 1996.

6. Янбухтина А. Г. Народные традиции в убранстве башкирского дома. Уфа: Китап, 1993.
4. Spegal'skiy, S.P. (1972) Zhilishche Severo-Zapadnoy Rusi IX-XIII vv. [Dwelling in North-Western Russia of the 9th-13th centuries] Leningrad: Nauka.

5. Stepin, V.S. (1996) Epokha peremen i stsenarii budushchego [The Era of Change and Future Scenarios]. Moscow: Institute of Philosophy, RAS.

6. Yanbukhtina, A.G. (1993) Narodnye traditsii v ubranstve Bashkirskogo doma [Folk Traditions in the Decoration of the Bashkir House]. Ufa: Kitap.

\section{Полная библиографическая ссылка на статью:}

Михеева, Т. Б. Личность в мире родной культуры и общечеловеческих ценностей / Т. Б. Михеева, Д. С. Саъдуллаев // Наследие веков. - 2020. - № 1. - С. 36-43. DOI: 10.36343/SB.2020.21.1.003

\section{Full bibliographic reference to the article:}

Mikheeva, T. B. \& Sadullaev, D. S. (2020) Personality in the World of Culture of Origin and Universal Values. Nasledie vekov Heritage of Centuries. 1. pp. 36-43. (In Russian). DOI: 10.36343/SB.2020.21.1.003 